\title{
Diverse and integrative explanations for plant productivity-richness relationships
}

Authors: Zhenhong Wang ${ }^{1 *}$, Juan Arratia ${ }^{2}$, Ting Yan ${ }^{1}$, Cong Zhang ${ }^{1}$, Alessandro Chiarucci ${ }^{3}$

Affiliations:

${ }^{1}$ Key Laboratory of Subsurface Hydrology and Ecological Effects in Arid Regions, Ministry of Education, Chang an University, Xi'an, China; School of Environmental Science and Engineering, Chang`an University, Xian 710064, China

${ }^{2}$ AGMUS Institute of Mathematics, Caribbean Computing Center for Excellence, 21150, San Juan, Puerto Rico, USA

${ }^{3}$ Department of Biological, Geological and Environmental Science, University of Bologna, Bologna, Italy

*Correspondence to: w_zhenhong@126.com

Abstract: The plant productivity-richness relationship (PPR) is one of the most debated and important issues in ecology. There have been distinct stages in the research of this issue, including the discovery of the different PPR shapes, respective tests of influencing processes, and integrative research with vegetation investigation, manipulation experiments, and theoretical analysis. The debate largely focuses on what the dominant shapes and underlying mechanisms are. Recent integrative research works following analyses of respective processes affecting PPR have found that the humped, asymptotic, positive, negative, and irregular shapes of PPR are linked to each other. One shape of PPR may change into another. The balance between positive and negative processes determines the different shapes of PPR. Plant diversity has a globally positive effect on plant productivity.

Keywords: plant diversity, plant productivity, humped pattern, intrinsic rate of species richness, complementary effect, resource availability, disturbance, species pool effect, competition exclusion, process integration

Plant diversity and productivity are two fundamental properties sustaining ecosystem structures and functions. Only when there are diverse plant species in an ecosystem can the ecosystem acquire sustainable primary productivity and stability $(1,2)$. Correspondingly, the ecosystem is able to supply ecosystem services, such as sequestration of $\mathrm{CO}_{2}$, release of oxygen, production of wood, regeneration of clean water resources, and control of soil erosion. Therefore, PPR is considered a core issue by ecologists worldwide $(3,4)$.

Early ecologists found that, in natural ecosystems, plant species richness continually increased with increasing plant productivity, but when plant productivity reached a high level, species richness conversely decreased with a continual increase in productivity. PPR showed a humped (or unimodal) curve $(5,6)$. Further work indicated that there were also positively and negatively linear and asymptotic relationships between plant productivity and species richness. Ecologists have even found U-form and irregular forms of the relationships. Therefore, ecologists began to debate the general shape and underlying mechanisms (7-10). When ecologists considered the effects of plant productivity on species richness or diversity patterns, the effects of plant species richness on productivity were also diverse in the shapes of PPR based on numerous investigations in natural ecosystems (11). Ecologists conducted many experiments of species assembly under consistent influencing conditions in the field to clarify the relationships. The results showed that the dominant PRR shape was positive or asymptotic. Inconsistencies in the results from manipulation experiments and natural ecosystems have led to more debate than in the earlier stages $(7,12,13)$.

In fact, there are two potential relationships regarding PPR: (1) the plant productivity-species richness relationship (PSRR), in which plant productivity is an independent variable and species richness is a dependent variable, which can elucidate the patterns of diversity affected by productivity with other processes (Fig. 1); (2) 


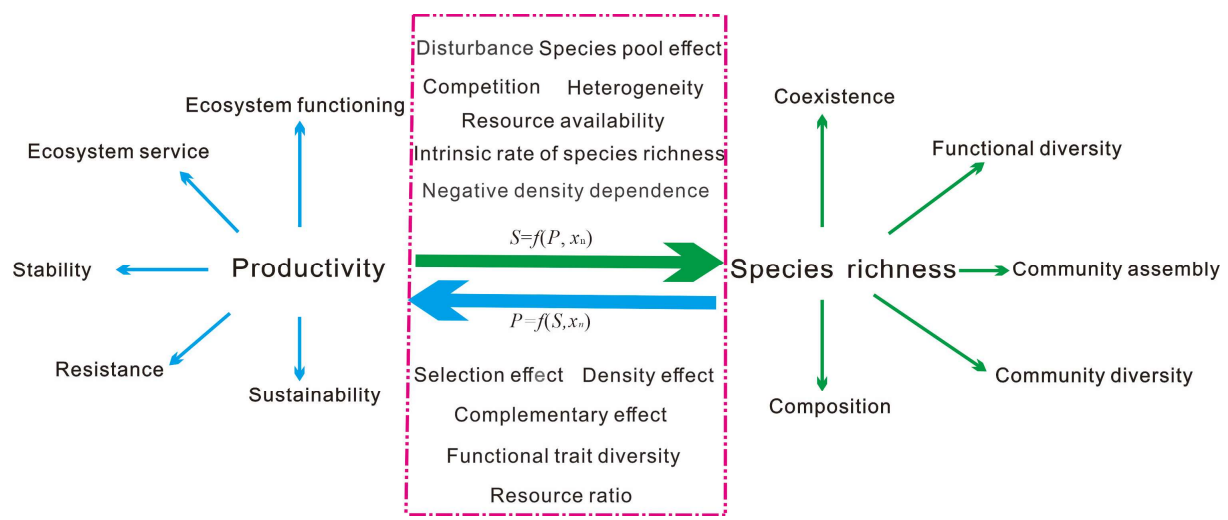

Fig. 1 PSRR and SRPR. Primary processes influencing PSRR and SRPR are in the dashed box. Big blue arrows represent SRPR linking with ecosystem properties at the left. Big green arrows represent PSRR linking with community structures. S: species richness; $P$ : productivity; $x_{n}$ : biotic and abiotic processes.

species richness-plant productivity relationship (SRPR), i.e., the feedback relationship to PSRR, in which species richness is conversely an independent variable and plant productivity is a dependent variable, which can be used to clarify the effects of plant diversity on plant productivity as well as on ecosystem functioning, stability, and services directly related to productivity (14, 15, Wang et al., 2017, 2019). PSRR and SRPR almost link with all key processes and issues in ecology (Fig. 1). Recently, ecologists have conceptually and methodologically revised the approaches that were used in the past. They typically identify the respective processes affecting plant species richness and productivity from numerous studies and integrally quantify the positive or negative effects of these processes with structural equation modeling $(2,3)$. Alternatively, ecological dynamical models are used to combine the effects of these processes on PPR after the positive or negative effects of these processes are identified from previous studies, following which the shapes of PPR with observed data are derived and validated (14-16). Consequently, all shapes of PPR occurring in past studies can be perfectly explained.

\section{A history of determining the SRPR and PSRR shapes SRPR}

The earliest ecologist concerned about PPR was Darwin (17). He proposed that more diverse plant communities are more productive. This is a perspective on a positive SRPR. Theoretical research also showed a positive relationship for SRPR about 100 years later (18). However, in the studies of New York old fields, where herbaceous perennial grasses and dicots were the principal components of the successional flora over the last few decades, average net productivity was negatively related to species richness, while total net productivity was not related to species richness (19). Ecologists considered that diverse ecosystems could avoid environmental degradation and maintain yield, thus proposing a diversity-sustainability hypothesis to support the positive SRPR $(20,21)$. The experimental studies of the effects of diversity on a variety of biogeochemical processes indicated that diverse ecosystems could indeed decrease the loss of soil nutrients and maintain soil fertility to support biomass production, consequently verifying the diversity-sustainability hypothesis $(21,22)$.

In the 1990s, ecologists conducted species-assembling experiments in grasslands to test SRPR under the conditions of consistent biotic and abiotic influencing factors in northern America and several countries of Europe $(23,24)$. These long-term experiments designed species richness gradients from one to several tens of species to test the shapes of SRPR. These experiments provided convincing positive or asymptotic SRPRs, even when legumes were excluded from the plant community assemblies. Moreover, ecologists discovered that the nitrate necessary for plant growth in the root zone and below the root zone was significantly decreased and the soil nitrogen utilization was increased with increasing plant species richness, thus strongly supporting the diversity-sustainability hypothesis (25). Ecologists were confident about the positive or asymptotic SRPR at the end of the 1990s and proposed selective and complementary effects to explain the relationship $(24,26,27)$.

Further experiments and observations from different continents as well as data from earlier studies previously unknown to ecologists concerning SRPR have been used to analyze SRPR in the 21st century. A report by some leading ecologists proposed that certain combinations of species were complementary in their patterns and were able to increase their average rates of productivity and nutrient retention (28). A meta-analysis indicated that in 44 experiments of species manipulation, mixtures of species produced an average of 1.7 times more biomass than monocultures, thus verifying positive SRPR; however, by comparing the mean biomass production of polycultures 
and monocultures for the single most productive species in these experiments, 10 positive, 52 non-significant, and 22 negative SRPRs were found (11). Under the conditions of no controlled biotic and abiotic factors affecting SRPR in the field, a negative SRPR was found to be very common, including in three forest types in British Columbia and Albe (29), the Park Grass Experiment (30), and the prairie-forest ecotone of north-eastern Kansas (31). These different findings resulted in a few inconsistent points regarding the shapes of SRPRs and underlying mechanisms $(12,13)$.

\section{PSRR}

Ecologists began to discuss productivity as one of the reasons for temperate/tropical diversity gradients in the 1960s (5,32). Following this, the existence of a humped PSRR was found (33). The monotonic PSRR curve was first motioned in a theoretical study, which included positively and negatively monotonic PSRRs (34). However, negatively monotonic or mutually unrelated PSRRs were observed in natural grassland and algae communities until the 1980s (35). A positively monotonic PSRR was first described by the linear relationships between tree species richness and annual evapotranspiration as an indirect index of productivity (36). During this stage, humped and positive PSRRs were the widely accepted shapes of PSRRs, and the two shapes also played a major role in the clarification of diversity patterns $(37,38)$. Ecologists claimed that a humped PSRR was the only type with either empirical or theoretical support, and that other types, such as positive shapes, might only constitute one or two parts of the humped PSRR in the early stage of 1990s (5). These points are primarily based on the relatively fewer results on PSRR before the 1990s.

Many field studies on PSRRs were conducted on different continents in the 1990s. The shapes of PSRRs were diverse, and ecologists did not agree that the humped PSRR was a sole diversity pattern. For example, a humped PSRR in a Mediterranean salt marsh, Caribbean phytoplankton community, and grasslands and shrubs (39), a negative PSRR in no grazed plots of two Louisiana coastal marshes and beaver meadows (40, 41), a positive PSRR in a model assemblage of plant species, beaver meadows, and open grasslands and half-shrub areas (41, 42), and unrelated PSRRs $(39,42)$ were found.

Several meta-analyses directly provided the percentages of the different shapes of PSRR during the first decade of the 21 st century $(7,8,10)$. In these articles, humped and positive PSRRs obtained high percentages, but these results were considered scale-dependent and were often confused in terms of the grain, focus, and extent of PSRR (8, 10). Consequently, ecologists began with the next round of research with new approaches for avoiding these weaknesses. The new round of exploration indicated that diverse shapes of PSRR still occurred, such as positive and humped PSRRs in a subtropical forest of Puerto Rico, USA (43), dominant humped PSRRs in the northeastern sections of China and USA (44), and negative PSRRs in natural stands of Central Europe and managed grasslands of Germany (45, Socher et al., 2012). Therefore, the shapes of PSRR still continue to be debated $(1,46)$.

Scientists had comparatively more consistent points on the dominant shape of SRPRs, i.e., positive or asymptotic, than on the dominant shape of PSRRs $(26,47,48)$. This is because ecologists can conduct manipulative experiments in plots over a short time to test productivity with increasing species richness in addition to vegetation investigation and theoretical modeling. However, ecologists have also found it difficult to determinate the relative contribution of increasing species number and changing plant traits to increasing productivity with species richness, which is a focus of much debate $(49,50)$. After ecologists carefully compared the roles of plant traits with species richness in productivity, they were very confident of the positive effects of species richness on productivity, while other shapes of SPRR still occurred with a small percentage (47, 51). However, for PSRR, ecologists could only adopt vegetation investigation and theoretical modeling to test the shapes of PSRR. They could not design a gradient of productivity to test the change in species richness with increasing productivity, as an increase in species led by productivity often occurred at an evolutionary time scale jointly affected by various abiotic and biotic factors, such as climate, dispersal, and species pool. Therefore, the debate on PSRR is more intense than that on SRPR.

\section{Different explanations for the shapes of PSRRs and SRPRs}

In long-term studies, ecologists have suggested many theories, hypotheses, or processes to explain PSRR and SRPR. Generally, processes affecting PSRR or SPRR, or used to support these theories and hypotheses, have either positive or negative effects, or both positive and negative effects on species richness, plant productivity, and further on SPRR or SRPR (Table 1). These processes have been widely accepted by ecologists to explain the shapes of PSRR and SRPR $(14,15)$. Here we generalize them as follows.

(1) Intrinsic rate of increase in species richness with increases in plant productivity (IRISR). IRISR is defined as a positive process directly increasing plant species richness according to the metabolic theory of ecology (MTE) and species energy theory (SET). MTE states that available resources such as high ambient temperature and precipitation in comparatively lower than higher longitude regions can generate a high metabolic rate and, 
consequently, increase plant productivity from biochemical kinetics. A high metabolic rate and productivity increase the mutation rate of genes and plant fecundity rates to cause rapid speciation, resulting in higher species richness in communities for a long time $(52,53)$. Thus, an increase in species richness is inherent to increasing productivity. SET assumes that a certain number of resources is required to maintain at least one individual of a given species; therefore, as the quantity of resources (i.e., potential productivity) increases, the quantity of individuals increases, and more rare species are also able to maintain viable population sizes in a community, which leads to reduced local extinction and increased species diversity $(54,55)$. SET is based on the premise that increases in the number of individuals and productivity are positively correlated, and consequently productivity is simply a sum of individual growth; these actually occur only when there is low resource availability or productivity levels with weak or no competition stress (56).

(2) Intra- and inter-specific competition effects (IICE). IICE include multiple processes such as competition stress, competitive exclusion (ICE), and assemblage-level thinning (ALT) $(35,38)$. Most competition theories indicate that mortality is not equal among species due to inter-specific differences in resource use, individual size, and growth rates (57). Competition for limiting resources becomes increasingly important at high levels of productivity; thus, resource acquisition and growth by the dominant species suppress and, eventually, exclude the subordinate species (i.e., ICE), thereby yielding a relatively species-poor assemblage $(38,57,58)$. However, ALT occurs because of equal mortality among species and thinning alone in habitats with abundant resources, and high plant productivity causes decreases in species richness, leading to the extinction of rare species $(5,59)$. ICE and ALT both explain decreases in plant species richness (i.e., a negative effect on species richness) at high resource availability

Table 1 Processes directly affecting species richness and productivity

\begin{tabular}{|c|c|c|}
\hline Ecological process & $\begin{array}{l}\text { Object that the process } \\
\text { affects }\end{array}$ & Citations \\
\hline IRISR & $(+)$ Species richness & $(9,53,57,60)$ \\
\hline IICE & $\begin{array}{l}\text { (-)Species richness; }(- \text { or }+) \\
\text { productivity }\end{array}$ & $(35,57,61,62)$ \\
\hline Competition stress & 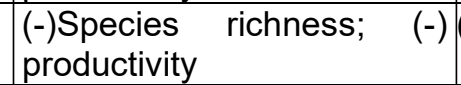 & $(35,38)$ \\
\hline Competitive exclusion & (-)Species richness & $(35,38)$ \\
\hline Assemblage-level thinning & $\begin{array}{ll}\text { (-)Species } & \text { richness; } \\
\text { (+)productivity } & \end{array}$ & $(57)$ \\
\hline Resource availability & $\begin{array}{l}\text { (+or-)Species } \\
\text { (+)productivity }\end{array}$ & $(9,62)$ \\
\hline Disturbance & $\begin{array}{l}\text { (- or }+ \text { )Species richness; } \\
\text { (-)productivity }\end{array}$ & $(63-65)$ \\
\hline Species-pool effect & $(+)$ Species richness & $(66,67)$ \\
\hline Ecological and limiting similarities & $\begin{array}{ll}\text { (-)Species } & \text { richness; } \\
\text { productivity } & \end{array}$ & $(67)$ \\
\hline Differences of niches & $(+)$ Species richness; & (67) \\
\hline $\begin{array}{l}\text { Filtering effects by abiotic and biotic processes } \\
\text { (e.g., isolation, long-dispersal distance, unsuitable } \\
\text { establishment conditions, lack of seeds, and } \\
\text { differences in fitness and competitive ability) }\end{array}$ & (-)Species richness & $(68,69)$ \\
\hline Land area and scale increase & $\begin{array}{l}\text { (+)Species richness; } \\
\text { (+)productivity }\end{array}$ & $(66)$ \\
\hline Environmental heterogeneity & $(+)$ Species richness & $(70,71)$ \\
\hline Negative density dependence & (+)Species richness & $(72-74)$ \\
\hline Sampling effects & (+/0)productivity & $(12,27)$ \\
\hline Complementary effects & (+)productivity & $(12,27)$ \\
\hline Density effect & $\begin{array}{l}\text { (+)Species richness; } \\
(+ \text { or }- \text { )productivity }\end{array}$ & $(57,75)$ \\
\hline Imbalance in the supply of resources & (+)Species richness & $(9,62)$ \\
\hline Functional trait and its diversity & (+)Productivity & $(76,77)$ \\
\hline
\end{tabular}

Notes:,+- , and 0 represent positive, negative and no any effects, respectively. 
levels. However, ICE and ALT often have positive effects on productivity in a community when they eliminate the subordinate species or weak individuals with low resource-use rates. However, competition stress without ICE and ALT might weaken the growth of all species, generating a negative effect on productivity $(57,59,62)$. Clearly, the IICE on species richness and productivity are complex.

(3) Dynamic equilibrium hypothesis. The hypothesis is an early explanation related to different processes for PSRR (78). The hypothesis suggests several key factors: competition, disturbance, and productive habitat. Under this hypothesis, poor competitors are excluded rapidly in highly productive habitats with rare disturbance, leading to low diversity. A strong disturbance also results in the disappearance of unbearable plant species, leading to low species richness. With very frequent or very rare disturbances, diversity will remain relatively low in habitats of any productivity (79).

(4) Theory of resource competition. The theory uses resource heterogeneity, productivity, nitrogen, light, and disturbance to comprehensively explain PSRR and argues that very productive and very unproductive habitats have low resource heterogeneity (62). However, habitats with intermediate productivity have the highest resource heterogeneity and allow many species that rely on different resource conditions to coexist. Plants at low productivity are entirely limited by a soil resource such as nitrogen, and only the best nitrogen competitor can grow. At high productivity, dense plants are full of the habitats, and plant growth is entirely limited by light. Only the best light competitor grows $(37,79)$. In between, different micro-habitats have different nitrogen:light ratios, and different species are the best competitors in each type of micro-habitat, and thus many species coexist.

(5) Species-pool effect. Species pools are defined as a set of plant species with each species of a community, local, or regional flora being a member of any community, local, or regional species pool, with different degrees of probability. The probability is specifically regulated in a plant species assembly by the ecological and limiting similarities and differences in the niche, fitness, and competitive ability occurring among specific species (67). Species richness occurring on a particular scale, as well as the geographical extent of that scale, is dictated by the species-pool effect. The species-pool effect is weakened owing to filtering by abiotic and biotic processes (e.g., isolation, long-dispersal distance, unsuitable establishment conditions, lack of seeds, and differences in fitness and competitive ability) on immigrating species (66). These processes have a negative effect on species richness. The species-pool effect is also closely related to the geographical and evolutionary contexts, in that the species pool, delimited by a geographical region with high environmental heterogeneity, resource abundance, and rapid speciation, or a region in the center of biodiversity, possesses a greater species-pool effect (67).

(6) Disturbances. Intense disturbances from the natural world or humans, such as grazing, fire, severe windstorms, wave damage, land cover alterations, habitat fragmentation, and forest destruction, often alter plant productivity and species richness, primarily via a negative mortality-causing effect, and further regulate PSRR and SRPR (80). Urbanization and industrialization inevitably convert forest to other land cover types, altering soil biophysical and chemical properties, as well as animal and microbial communities, which likely has a negative effect on the maintenance of plant diversity and productivity (64). However, moderate disturbances, such as a moderate intensity of grazing and fires, often restrain the dominant plants and remove the litter and secondary biomass in forests, promoting the establishment of immigrated species, which in turn results in an increase in plant diversity and productivity - an indirect effect. Over the past 40 years, the "intermediate disturbance hypothesis" has been widely recognized as an ideal concept for explaining the effects of disturbances on species diversity patterns despite some ecologist's critiques due to theoretical weaknesses (63-65).

(7) Environmental heterogeneity. Environmental heterogeneity is scale-dependent, and, at the local-scale level (e.g., quadrats and plots), there are different configurations in resource types with various availability levels along with more complex configurations in abiotic and biotic resources and more heterogeneities in the environment (81). For example, five levels of $\mathrm{pH}$, depth, moisture, and nitrogen (i.e., four factors) in the soil are configured in a plot, and accordingly the environmental heterogeneity in the plot will exceed another plot in which only four levels of these four factors or five levels of three factors are configured. However, environmental heterogeneity primarily embodies differences in habitat and microclimate at landscape scales, such as the habitat differences among plant communities located in a valley, flatland, cropland, and beach of a river within a landscape $(70,71)$. Therefore, a set of relatively different species arises in different habitats, and the landscape contains more different species. Climate and physiography present obvious differences on regional scales, shaping various zonal vegetation types, such as deciduous coniferous forests, temperate deciduous broad-leaved forests, and tropical rain forests, distributed across different climatic zones (82). These vegetation types include a set of different species adapting to zonal climate, which regionally increases species diversity.

(8) Density effects. Density effects are based on species-energy theory, which suggests positive relationships between species richness and the total number of plants in plant communities (75). Plant density increases with 
increasing species richness, thus leading to high biomass production at low inter-specific and intra-specific competition levels. Increasing plant density also results in high plant species richness in a plant community with the maintenance of rare populations and low assemblage-level thinning — an effect that appears to have been previously ignored (57). However, inter-specific competitive stress on the growth of plants occurs at high species richness levels and causes a decrease in the average size and mass of individual plants, and thus plant productivity $(38,58)$. Density effects reflect a characteristic of plant species richness by increasing plant density to increase plant productivity, which is similar to $r$ selection as a plant strategy.

(9) Negative density dependence (NDD). NDD is a process by which population growth rates decline at high densities as a result of natural enemies (e.g., predators, pathogens, or herbivores) and/or competition for space and resources (74). Numerous studies explicitly or implicitly assume that a stronger NDD maintains higher species diversity in communities and have documented the existence of NDD in one or several plant species. Negative interactions among plant species are known as conspecific NDD. Conspecific NDD is considered a dominant process that prevents the erosion of biodiversity in tropical forests, not only by limiting populations of common species but also by strongly stabilizing populations of rare species (73). This theory argues that a rare species is more likely to experience strong positive growth rates, whereas a dominant species has a large range of relative abundance values over which it experiences negative growth rates. The positive and negative effects are crucial for helping rare species resist extinction and decrease the excessive individuals of dominant species and maintain the diversity of the plant community (72).

(10) Selective and complementary effects. The selection effect is the standard statistical covariance effect, and specifically species yields in a plant community are on average higher than expected on the basis of the weighted average monoculture yield of the component species, as a diverse community stochastically contains highly productive species $(12,27)$. The complementary effect actually refers to an effect caused by differentiation in resource use and/or facilitative interactions among plant species, which become the main drivers of increasing productivity at higher levels of species richness $(11,12)$. However, the selective effect is challenged by the so-called zero-sum game, which states that, in a diverse community, the low-productivity species also occur at a high probability and offset the effect of highly productive species, thereby reducing the effect to zero $(11,83,84)$. However, the assembly of low-productivity species selected is complementary in resource use and can possibly bring about relatively higher productivity than a monoculture, which does not reduce the sampling effect to zero.

(11) Resource availability. Resource availability includes two characteristics. First, the summed abundance of various resource types, such as temperature, sunlight, water, and mineral nutrients, directly affects plant species richness and productivity by controlling sizes of populations, growth of organisms, and the probability of stochastic extinction according to SET $(9,85)$. Second, relatively higher quantities of limited resources ensure that weaker competitors are able to capture the limited resources based on the resource ratio theory for the maintenance of a population. However, the theory also states that the imbalance in the supply of two or more resources, relative to the stoichiometric needs of competitors, can dictate the strength of the competition and, in turn, the diversity of coexisting species $(9,62)$.

(12) Theory of species' functional traits and diversity. Species' functional characteristics strongly influence ecosystem properties $(76,77)$. Functional traits operate in a variety of contexts, including the effects of dominant species, keystone species, ecological engineers, and interactions among species. Relative abundance is not always a good predictor of the ecosystem-level importance of a species, as even relatively rare species, possibly an especial species, can strongly influence the pathways of energy and material flow (76). Increasing the diversity of functional traits and interspecific interactions will ensure different ecosystem properties, ecosystem sustainability, and ecosystem stability (77).

\section{Integrative explanation of PSRR and SRPR Points on integration}

The above theories, hypotheses, or processes evidently promote the understanding of PSRR and SRPR. However, they can only explain the dominant shape or a component of PSRR and SRPR. The dominant humped shape of PSRR and the dominant asymptotic or positive shape of SRPR are always challenged in studies, because the results from assembly experiments, field investigations, and mathematical modeling have indicated other shapes, including the negative monotonic, irregular, unrelated, or even U-shaped $(10,46)$. These different shapes are the main reason why ecologists have been intensely debating the two relationships over the past several decades $(5,57$, $59,86)$. Although ecologists have consistently adopted standardized approaches to reconcile the differences in the shapes and clarify the underlying causes, the different shapes of PSRR and SRPR have still been reported in recent studies $(1,46,60,87,88)$.

Some authors argue that PSRR and SRPR are variable and complex because they are governed by many abiotic 
and biotic processes and different methods that are scale dependent $(1,13)$. It may be better if ecologists focus on studying more shapes of PSRR and SRPR, but for the causes explaining these shapes, an integrative analysis of various processes over bivariate relationships should be conducted to explain the diversity of PSRR and SRPR $(1,13,89)$. Ecological processes affecting plant productivity, species richness, and their relationship often have either a positive or negative effect, and some have even two effects simultaneously $(5,9,79)$. Completely understanding PSRR and SRPR and their underlying mechanisms would be beneficial if the following steps are conducted: (1) the identification of the respective effect of each process on PSRR and SRPR from numerous studies; (2) the use of suitable models to construct and combine the respective effects of these processes into a logical comprehensive effect on PSRR and SRPR; (3) the derivation of the shapes of PSRR and PSRR based on the integrative models of processes; (4) the use of observed data to verify the derived shapes and identify underlying mechanisms and roles of processes $(1,14-16)$.

\section{Early studies of integration}

Early studies were primarily concerned with integrative theoretical methods for predicting the variation in species richness and coexistence related to PSRR, such as the non-equilibrium interaction model (NEIM), multispecies patch-occupancy model (MPOM), and resource-ratio model (RRM) $(62,78,90)$. NEIM assumes that most communities exist in a state of nonequilibrium where competitive equilibrium is prevented by periodic population reductions and environmental fluctuations; correspondingly, a dynamic balance may be established between the rate of competitive displacement and the frequency of population reduction, resulting in a stable level of diversity (78). In MPOM, a pattern of diversity is described with the changes in colonization rates, disturbance rates, and plant cover - a surrogate of productivity. The model elucidates the effect of disturbance on numerous competitors that compete for space and exhibit a competitive hierarchy, and quantifies PSRR (90). RRM explains the coexistence of competitive species based on their differing abilities to compete for pairs of resources where the ratio of abundance of the resources varies $(62,91)$.

In a modified neutral model suggested to explain PSRR and SRPR, all species are assumed to be ecologically identical and lack trade-offs in species characteristics (92). Based on the model, most documented patterns of disturbance-richness and productivity-richness relationships as well as the observed interactions can be explained well with the identification of different species responses to productivity and disturbance. In a modified multispecies patch-occupancy model, the separate effects of productivity and disturbance on species richness are synthesized to explain identified positive, negative, or humped PSRR (92). When a predicted productivity-diversity relationship is humped, productivity levels that maximize species richness increase with increasing disturbance; similarly, when a predicted disturbance-diversity relationship is humped, species richness moves to a high disturbance level with increasing productivity. A model of plant community for explaining the mechanism of coexistence integrates resource heterogeneity and recruitment limitation with and without any trade-off between reproductive and competitive abilities (93). The generated results include different levels of species richness with model parameters, number of species in a regional pool, degree of recruitment limitation, and level of heterogeneity. Different diversity-productivity patterns are demonstrated with different coexistence mechanisms, indicating that there is no reason to expect any general PSRR.

Three models of interspecific competitive interactions containing various numbers of randomly chosen species predict that, on average, productivity increases asymptotically with the original biodiversity of a community, ecosystem nutrient retention also increases with biodiversity, and the effects of biodiversity on productivity and nutrient retention increase with interspecific differences in resource requirements (94). The effect of plant diversity produces the typical asymptotical shape of SRPR (Fig. 2A). A mechanistic model of a spatially structured ecosystem in competition for a limiting soil nutrient shows that plant species richness does not necessarily enhance ecosystem processes, but it identifies two factors that could generate nutrient retention and high productivity: (i) complementarity among species in the space they occupy belowground and (ii) a positive correlation between mean resource-use intensity and diversity (95; Fig. 2B). These two factors have important implications for the understanding of SRPR, and the model also shows that the effect of species richness on productivity or other ecosystem processes is often masked by the effects of physical environmental factors.

The early integrative models were designed primarily based on the most documented patterns of disturbancerichness, productivity-richness, and interspecific competition-richness, as well as their interactions, combining the important factors that researchers suggested (or excluded) to explain these dominant shapes of PSRR and SRPR. However, among them, once the dominant shape is not supported by the results, theoretical studies shift their focus from both the dominant PPR shape and the purely bivariate relationship to other issues. This approach shows the effort revealing the mechanisms of PSRR and SRPR, but the oriented prediction methods might have weakened the universality of the results. 

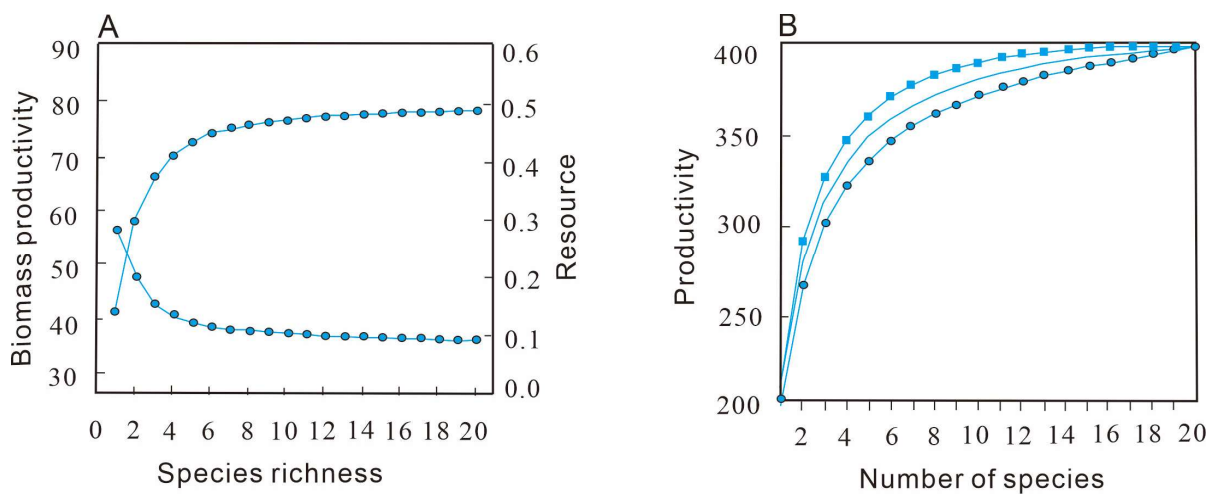

Fig. 2. Relationships among plant species richness, resource use, and productivity (A) Productivity increases and unconsumed resources decrease with increasing species richness [data from reference (94)]; (B) relationships among productivity, species richness, and resource-use intensity. Continual line: average resource-use intensity independent of specie species richness; circles and squares: species added in increasing and decreasing orders of resource-use intensity, respectively [data from reference (95)].

\section{Recent integration}

Grace et al. established a causal network for the humped shape of PSRR, in which the hump was assumed as a basic shape (1). The influencing processes and shapes of PSRR were quantified using structural equation modeling. Unexpectedly, this analysis did not support the assumed humped shape of PSRR, but conversely revealed other shapes and corresponding influencing processes. This exercise shows how causal networks are established by possible hypotheses and explicit tests to explain PSRR as an abstracting system, providing powerful predictions beyond bivariate analysis. Based on this idea, further structural equation modeling was used to integrate competing theories into a multi-process hypothesis and evaluate the hypothesis using the global data of 1,126 plots at grassdominated sites around the world (2). The variables measured included plant species richness, productivity, and total biomass along with many drivers including soil fertility, climate, heterogeneity, soil suitability, and shading. In contrast to a bivariate model, the modeling explained $61 \%$ of the variation in richness at the levels of sites and plots and quantified the roles of processes and other drivers in the regulation of PSRR and SRPR (Fig. 3).

In an additional integrative study, field observations from 6,098 forest, shrubland, and grassland sites across China were collected, and the direct effects of climate, soils, and human impacts on soil organic carbon (SOC) storage versus the indirect effects mediated by species richness, aboveground net primary productivity (ANPP), and belowground biomass (BB) were integrally quantified with structural equation modeling based on multiple hypothesized theories (3). The modeling showed a positive SRPR and a positive biomass - SOC relationship. Favorable climates (high temperature and precipitation) had a consistent negative effect on SOC storage, but a positive effect on species richness, ANPP, and BB. The positive relationships of species richness with ANPP and BB offset the negative effect of favorable climate on SOC. Maintaining high levels of diversity can enhance soil carbon sequestration and help sustain the benefits of plant diversity and productivity (97). 


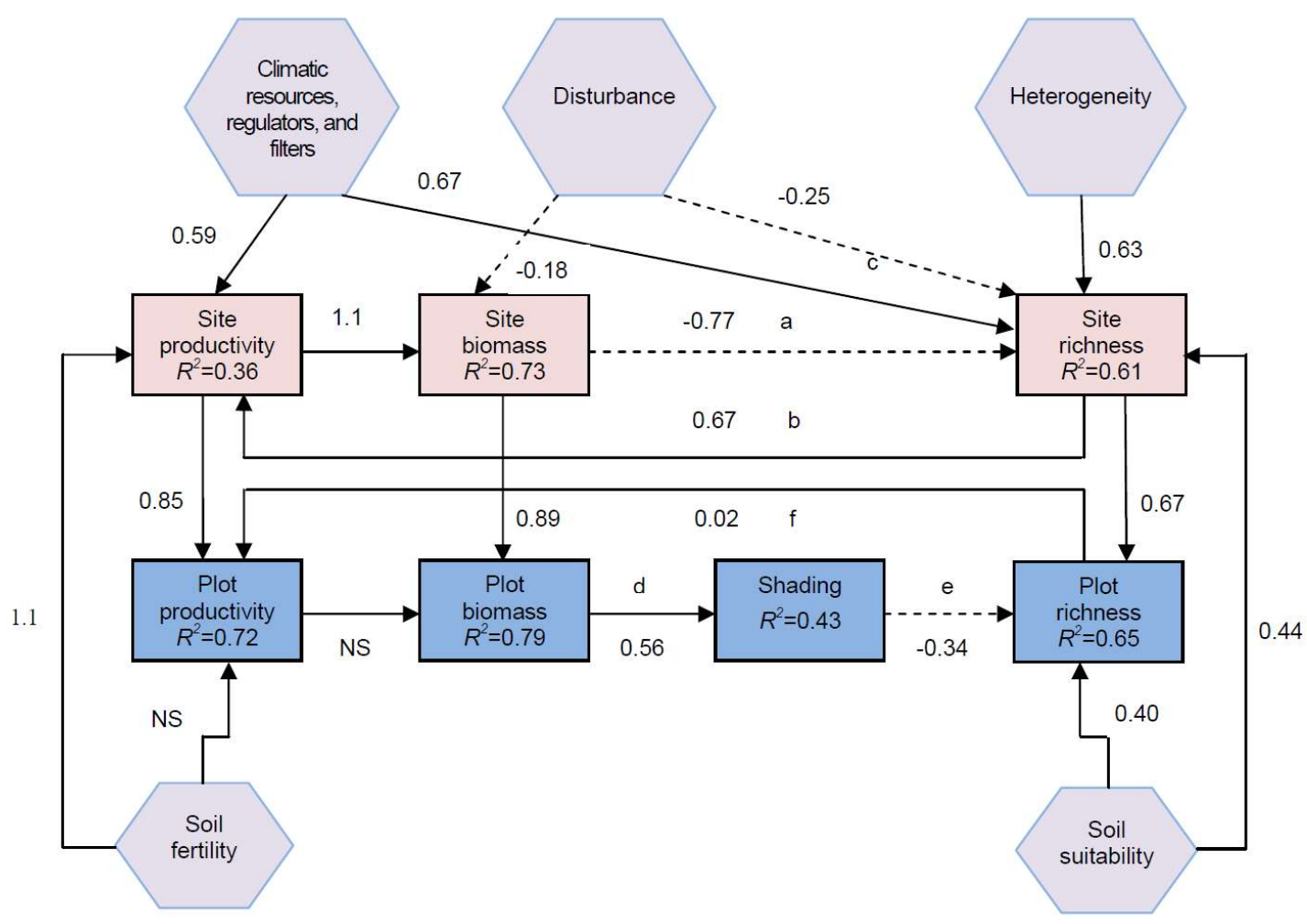

Fig. 3. Roles of multiple processes in PRR based on a structural equation model and field data. Solid arrows represent positive effects, and dashed arrows negative effects. Digits beside lines are the magnitude of effects [data from reference (2)].

On the basis of a previous long-term study of the relationships among productivity, environmental resources, and species richness, an empirical integrative model $P=\alpha \cdot f(X) \cdot S^{\theta}$ ( $P$, productivity; $X$, environmental resources such as soil and climate; $S$, species richness, $\alpha$, constant; $\theta$, the effects of species richness on productivity) was used to quantify the dependence of productivity on species richness (16). $\theta$ measures the marginal productivity - the change in productivity resulting from one unit decline of species richness - and reflects the strength of the effect of tree diversity on forest productivity, after accounting for climatic, soil, and plot-specific covariates). When $\theta>1$, the form of SRPR is concave-down; when $\theta=1$, the form of SRPR is positive; when $1>\theta>0$, the form of SRPR is asymptotic; when $\theta=0$, the form of SRPR is parallel (no effect); when $\theta<0$, the form of SRPR is negative. Data of plots taken from 777,126 permanent sample plots and more than 30 million trees across 8,737 species across 44 countries and territories and 13 ecoregions, most of which were taken at two consecutive inventories from the same localities, were used to explore the effects of species richness on productivity and verify these suggested shapes of SRPR at a global scale (Fig. 4). It was found that $\theta$ averaged 0.26 , indicating a positive effect on productivity, and a positively asymptotic shape was dominant. Other forms only occupied a small percentage. 

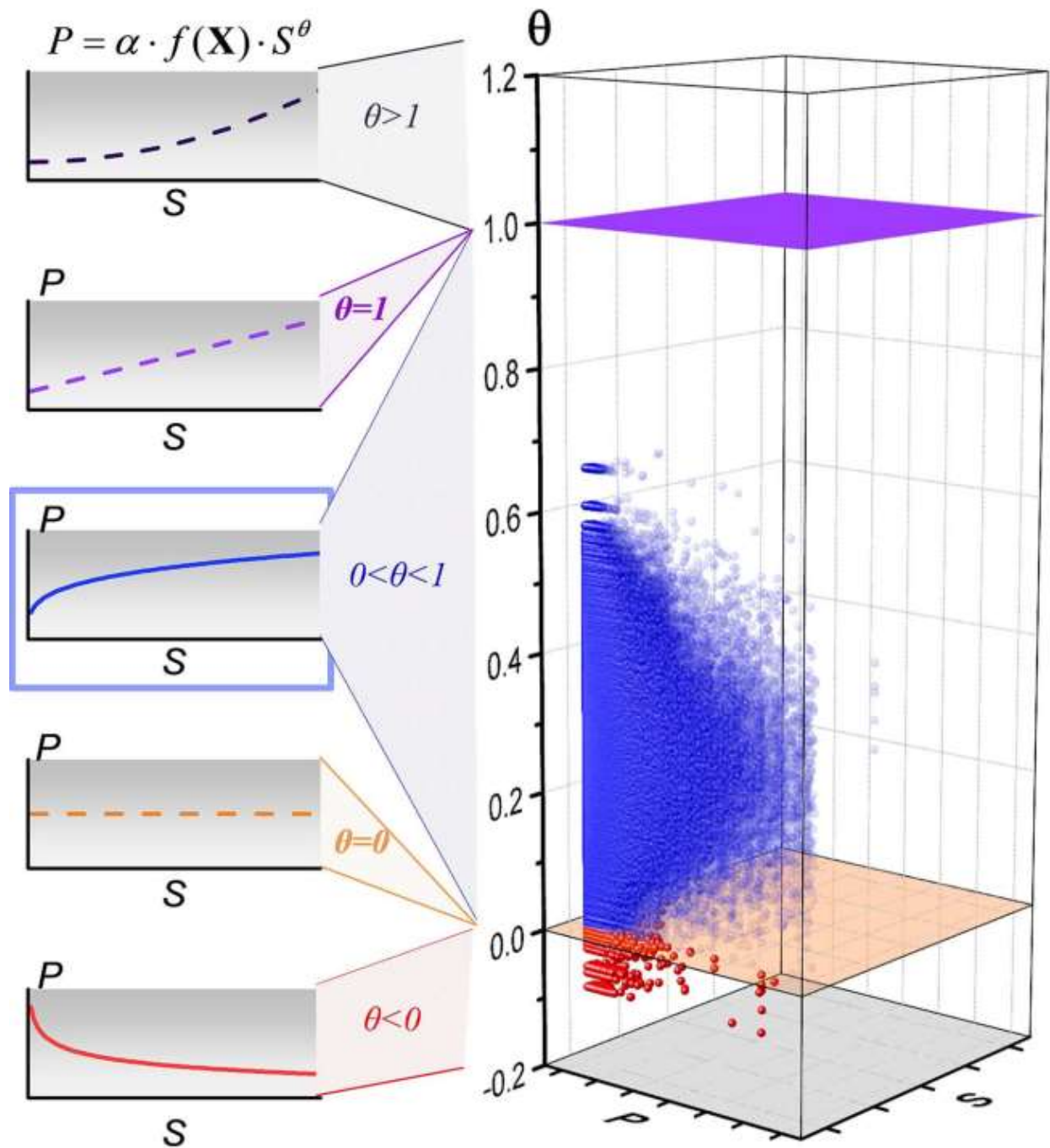

Fig. 4. Five shapes of SRPR and empirical evidence when the effective parameter of species richness $\theta$ is assigned different values. (Left) Shown are the different shapes of SRPR under different $\theta$ values. $\theta$ ranges from 0 to 1 corresponding to the positive and asymptotic SRPR (blue curve). (Right) The three-dimensional scatter plot shows the distribution of $\theta$ values estimated from observed data, indicating the dominance of asymptotic SRPR [data from reference (16)].

After the identification of processes generally widely-accepted by ecologists and their positive and/or negative effects on plant productivity and species richness in the related literature, a set of differential equations were established with an analysis of ecological dynamical systems to test the comprehensive effects of all these processes on PSRR and SRPR $(14,15)$. These processes were considered as the parameters of the set of the equations affecting PSRR and were assigned different values to represent the strengths of processes affecting PSRR. The values of the parameters were also altered to regulate the strengths of these processes in order to derive the shapes of PSRR richness and were explicitly defined as a dependent variable, with plant productivity as an independent variable, in the equations to quantify the effects of plant productivity on species richness. Next, the models of SRPR (i.e., the feedback relationships to PSRR) were derived, in which plant productivity was conversely determined as a dependent variable and species richness as an independent variable. The five typically documented forms of PSRR and the dynamics of IICE and species pool effects affecting these shapes with increasing productivity were derived with the set of integrative equations and verified by field data (14; Fig. 5). The PSRR shapes could change from one shape into another, with the different values of parameters representing the strength of the processes. As a set of the same parameters as PSRR was used in the equations of SRPR, the shapes of the two types of SRPR could also be 
derived: (1) SRPR with species richness continually presenting monotonic increases, which has long resulted in numerous ecologists trying to clarify the effects of species richness on plant productivity by manipulation experiments, field investigations, and theoretical analyses $(11,12,26)$; (2) the SRPR with species richness continually presenting nonmonotonic increases. Abundant empirical studies (compiled over several decades) on various terrestrial, freshwater, and marine taxa from different regions of the world have documented all these derived PSRR and SRPR shapes $(1,7,8,10,16)$. These studies also show that the dominant shape of PSRR is humped, while that of SRPR is asymptotic, with no exclusion of other shapes $(47,84,99)$.
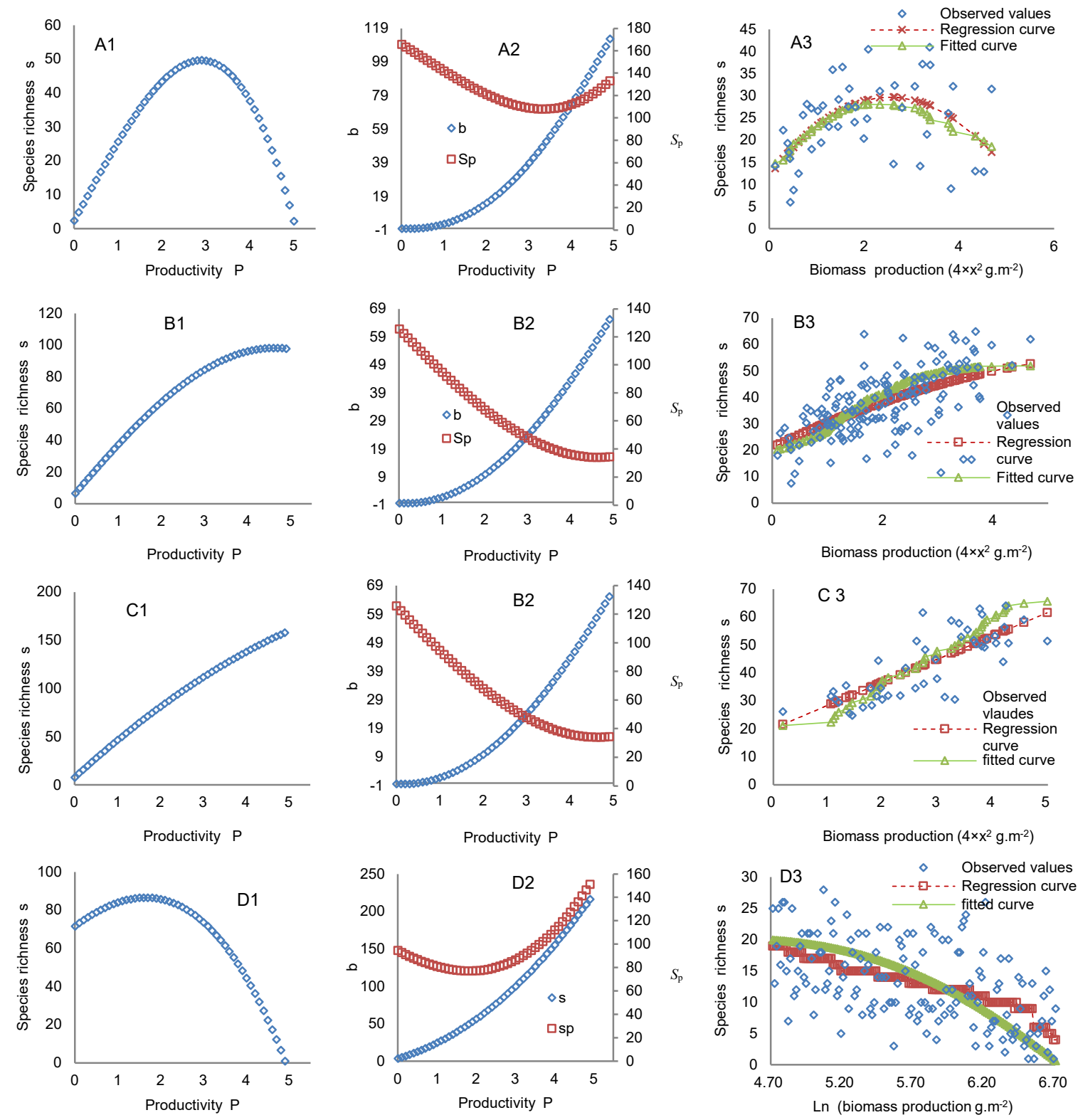

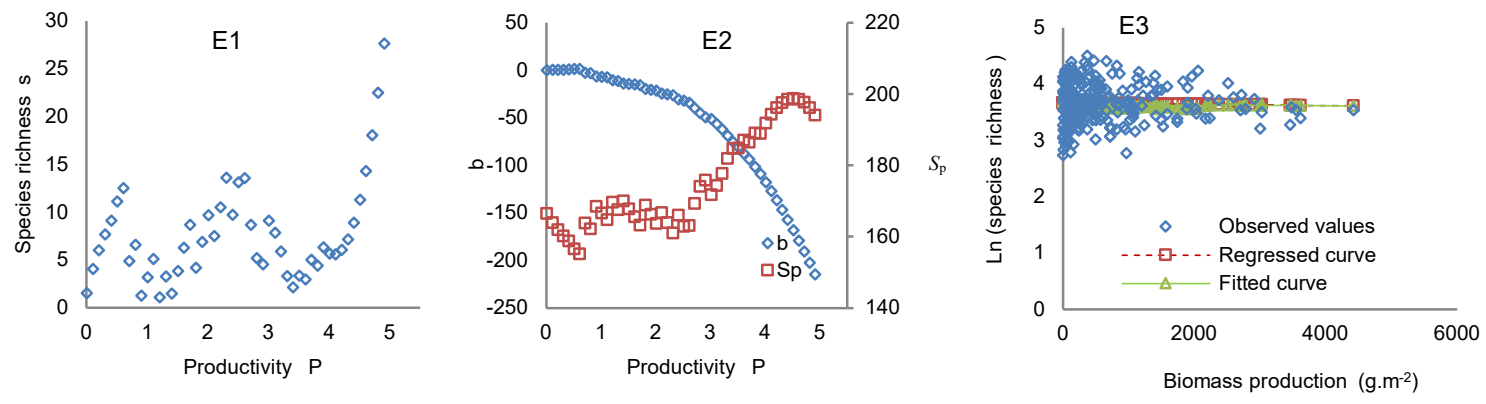

Fig. 5 Typical shapes of PSRR. A1-E1 represent the humped, asymptotic, positive, negative, and irregular shapes, respectively, derived by integrative equations combining almost all process affecting PSRR; A2-E2 indicates the dynamics of IICE $(b)$ and potential species-pool effect $\left(S_{p}\right)$ directly affecting the shapes of PSRR (14). A3-E3 are observed species richness along a productivity gradient at local sites in Germany, Czech Republic, Russia (87), the USA (31), and Australia (98), respectively. Regression curves are fitted based on these observed species richness and productivity. Fitted curves are the results fitted with the integrative equations based on these observed data. There was no significant difference between fitted and observed species richness.

The above integrative methods reveal the links between the different shapes of PSRR and SRPR and the roles of different processes in the real world $(2,14,16)$. If there are different strengths of processes to integrally act on species richness and productivity, different PSRR and SRPR shapes will arise (14, 15). Concretely, when the integrated positive processes are dominant, the shape of PSRR or SRPR is a positively linear or asymptotic pattern; when the integrated negative processes are dominant, the shape of PSRR or SRPR is a negative pattern; and when the integrated positive and negative processes are successively dominant, the shape of PSRR or SRPR is humped. Integrative methods can explain all observed PSRR and SRPR from dynamical mechanisms. In the integrative methods, the following three points are clearly indicated: (i) ecological processes that have a positive or negative effect on PSRR and SRPR vary temporally or spatially; (ii) the processes that have a strongly positive effect at one productivity or richness level might have a weakly positive or negative effect at another productivity or richness level (74); and (3) the combination of all positive and/or negative processes into a total effect (it may be positive or negative) radically determines the shapes of PSRR and SRPR $(14,16)$.

\section{Conclusions}

The respective (or diverse) and integrative research works on ecological processes affecting PRR represent two types of methods (Fig. 6). Respective research can test if one process has effects on PRR and can further reveal the underlying mechanisms. Integrative research can test the relative roles and interactions of processes in the regulation of PRR in the real world, as well as the relationships between the PRR shapes. PRR is considered as a core ecological issue across populations, communities, ecosystems, and even landscapes. Ecologists have long been concerned about the ecological processes affecting PRR, which has actually promoted the establishment of a series of ecological theories and the development of ecology despite a long-term debate on PRR. The relationships among metabolic rates related to resource availability and productivity, gene mutation rates, and increasing plant diversity are evolutionarily worthy of emphasis in future studies of PRR. In the integrative effects of processes on PRR, it is critical to identify the relative importance, scale-dependence, and interactions of processes in natural plant communities. Remarkable progress in PRR studies has been made despite intense debate. However, ecologists will need to carefully distinguish the two types of PRR affected by respective and integrative processes, as the confusion between the two relationships contributes to an additional source of debate. 


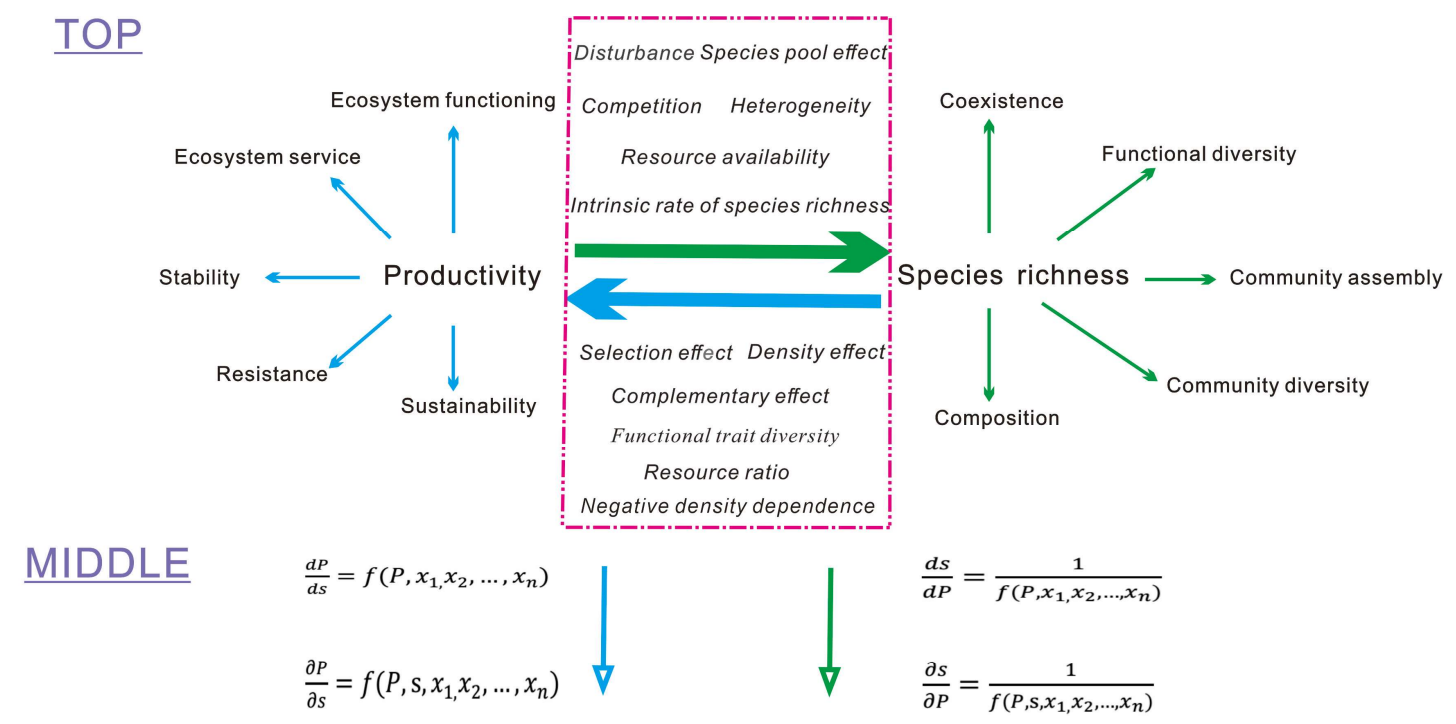

BOTTOM
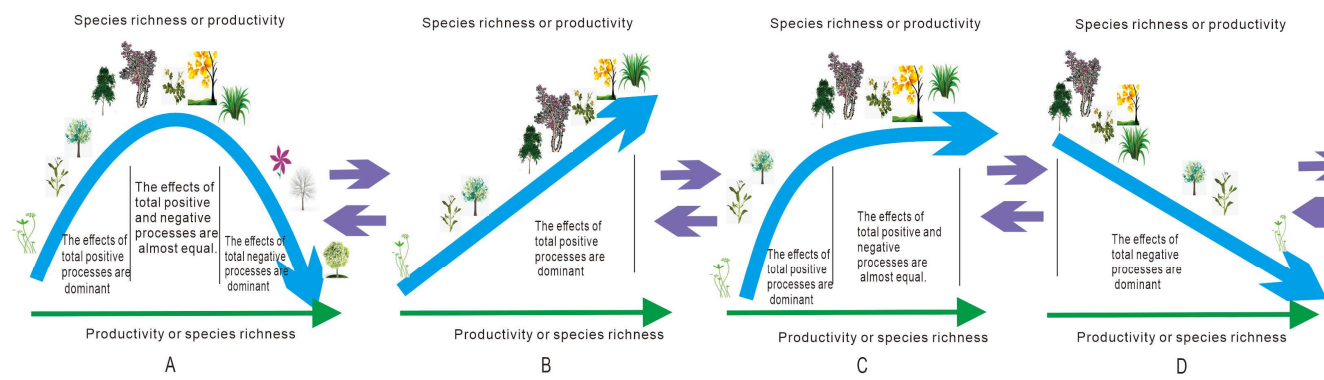

D

Species richness or productivity

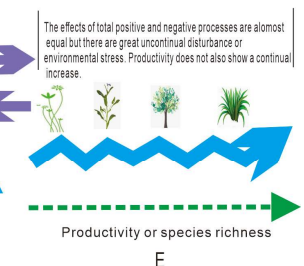

E

Fig. 6 Ecological processes respectively and integrally act on PRR. In the top layer, the green arrow indicates that productivity is an independent variable with other processes that affects species richness related to other diversity patterns, while the blue arrow indicates that species richness is an independent variable with other processes that affects productivity related to ecosystem nature. In the dashed box, different processes are considered to directly or indirectly act on productivity or species richness and consequently change PRR. In the middle layer, the first and second equations reflect the rates of change in productivity (a dependent variable) with species richness (an independent variable), respectively, and integrate different processes to derive the shapes of PSRR. The third and fourth equations reflect the rates of change in species richness (a dependent variable) with productivity (an independent variable) and integrate diverse processes to derive the shapes of SRPR. The bottom layer shows the results of the diverse shapes of PRR derived by integrative analysis and observed from the field. (A) Humped; (B) positive; (C) asymptotic; (D) negative; $(E)$ irregular. $A$ is a dominant shape of PSRR, but $C$ is a dominant form of SRPR under no exclusion of other shapes.

\section{Acknowledgments}

This work was supported by grants from the Fundamental Research Funds for the Central Universities (No. 300102299303) and the National Natural Science Foundation of China (No. 40861015). We thank LetPub for its linguistic assistance during the preparation of this manuscript.

1. Grace, J.B., Adler, P.B., Harpole,W.S., Borer, E.T., \& Seabloom, E.W. 2014. Causal networks clarify productivity-richness interrelations, bivariate plots do not. Functional Ecology 28: 787-798. Doi. 10.1111/1365-2435.12269

2. Grace, J. B., Anderson, T. M., Seabloom, E.W., et al. 2016. Integrative modelling reveals mechanisms linking productivity and plant species richness. Nature, 529: 390-393. $10.1038 /$ nature 16524 
3. Chen, S.P., Wang,W.T., Xua, W.T., et al. 2018. Plant diversity enhances productivity and soil carbon storage. PNAS, 115(16): 4027-4032. Doi. 10.1073/pnas.1700298114

4. Benkwitt, C.E., Wilson, S.K., Graham, N.A. J. 2020. Biodiversity increases ecosystem functions despite multiple stressors on coral reefs. Nature Ecology \& Evolution 4: 919-926. Doi. 10.1038/s41559-020-1203-9

5. Abrams, P. A. 1995. Monotonic or unimodal diversity-productivity gradients: what does competition theory predict? Ecology 76: 2019-2027. Doi. 10.2307/1941677

6. Schmid, B. 2002. The species richness-productivity controversy. Trends in Ecology and Evolution 17: $113-114$. Doi. 10.1016/S0169-5347(01)02422-3

7. Mittelbach, G.G., Steiner, C.F., Scheiner, S.M., Gross, K.L., Reynolds, H.L., Waide, R.B.,Willig, M.R., Dodson, S.I. \& Gough, L. 2001. What is the observed relationship between species richness and productivity? Ecology 82: 2381-2396. Doi. 10.2307/2679922

8. Gillman, L.N., \& Wright, S.D. 2006. The influence of productivity on the species richness of plants: a critical assessment. Ecology 87:1234-1243. 10.1890/0012-9658(2006)87[1234:TIOPOT]2.0.CO;2

9. Cardinale, B.J., Hillebrand, H., Harpole, W.S., Gross, K., \& Ptacnik, R. 2009. Separating the influence of resource "availability" from resource "imbalance" on productivity-diversity relationships. Ecology Letters 12 475-487. Doi. 10.1111/j.1461-0248.2009.01317.x

10. Whittaker, R.J. 2010. Meta-analyses and mega-mistakes: calling time on meta-analysis of the species richnessproductivity relationship. Ecology 91: 2522-2533. Doi. 10.1890/08-0968.1

11. Cardinale, B.J., Wright, J.P., Cadotte, M.W., Carroll, I.T., Hector, A., Srivastava, D.S., Loreau, M. \& Weis, J.J. 2007. Impacts of plant diversity on biomass production increase through time because of species complementarity. Proceedings of National Academic of Science 104: 18123-18128. Doi. 10.1073/pnas.0709069104

12. Balvanera, P., Pfisterer, A.B., Buchmann, N., He, J.S., Raffaelli, D., \& Schmid, B. 2006. Quantifying the evidence for biodiversity effects on ecosystem functioning and services. Ecology Letters 9:1146-1156. 10.1111/j.1461-0248.2006.00963.x

13. Willig, M.R. 2011. Biodiversity and Productivity. Science 333: 1709-1710. Doi: 10.1126/science.1212453

14. Wang, Z.H., Chiarucci, A., Arratia, F.J. 2019. Integrative models explain the relationships between species richness and productivity in plant communities. Scientific Reports, 9:13730. Doi : 10.1038/s41598-01950016-3

15. Wang, Z.H. 2017. Process strengths determine the forms of the relationship between plant species richness and primary productivity. PLOS ONE, 12(11):e0185884. Doi: 10.1038/s41559-017-0225-4

16. Liang, J.J., Crowther, T.W., Picard,N., et al. 2016. Positive biodiversity-productivity relationship predominant in global forests. Science, 354: aaf8957,1-12. Doi:10.1126/science.aaf8957

17. Darwin, C. 1859. The origin of species by means of natural selection. London, Murray.

18. Ehrlich PR, Ehrlich AH. 1981. The extinction: the cause and consequence of the disappearance of species. New York: Random House.

19. Mellinger and McNaughton. 1975. Structure and function of successional vascular plant communities in central New York. Ecology Monographs 45: 161-182.

20. Ewel, J. J., Mazzarino, M. J. \& Berish, C. W. 1991. Tropical soil fertility changes under monocultures and successional communities of different structure. Ecological Applications 1: 289-302.

21. Swift M.J, \& Anderson, J. M. 1993. Biodiversity and ecosystem function in agricultural systems. In Biodiversity and ecosystem function. Eds Schulze, E.E., and Mooney, H.A., 361-384 (Springer, Berlin, 1993).

22. Vitousek, P. M \& Hooper, D. U. 1993. Biological diversity and terrestrial ecosystem biogeochemistry. In Biodiversity and ecosystem function. Eds Schulze, E.E., and Mooney, H.A., 361-384 (Springer, Berlin, 1993).

23. Hector, A., Schmid, B., Beierkuhnlein, C., Caldeira, M.C., Diemer, M., Dimitrakopoulos, P.G. et al.1999. Plant diversity and productivity experiments in European grasslands. Science, $286 . \quad$ Doi. org/10.1126/science.286.5442.1123

24. Tilman, D., Reich, P. B., Knops, J., Wedin, D., Mielke T, Lehman C. 2001. Diversity and Productivity in a long-Term Grassland Experiment. Science 294(5543):843-5. Doi: 10.1126/science.1060391

25. Tilman, D., Wedin, D., Knops, J. 1996. Productivity and sustainability influenced by biodiversity in grassland ecosystems. Nature, 379: 718-720. DOI: 10.1038/379718a0

26. Loreau, M., S.,Naeem,P.Inchasusti,J.Bengtsson, J. P.Grime, A.Hector, et al. 2001. Biodiversity and ecosystem functioning: current knowledge and future challenges. Science 294: 804-808. Doi : 10.1046/j.15231739.1995.09040742.x 
27. Loreau, M., A. Hector. 2001. Partitioning selection and complementarity in biodiversity experiments. Nature 412: 72-76. DOI:10.1126/science.1064088

28. Hooper,D.U., Chapin, III. F.S., Ewel, J.J, Hector, A., Inchausti, P., Lavorel, S., lawton, J.H., Lodge,D.M., Loreau, M., Naeem, S., Schmid, B., Setälä, H., Symstad, A.J., Vandermeer, J., Wardle, D.A. 2005. Effects of biodiversity on ecosystem functioning: a consensus of current knowledge. Ecological Monographs 75: 3-35. Doi: 10.1890/04-0922

29. Chen, H.Y.H., Klinka, K., Mathey, A.H., Wang, X., Varga, P. \& Chourmouzis, C. 2003. Are mixed-species stands more productive than single-species stands: an empirical test of three forest types in British Columbia and Alberta. Canadian Journal of Forest Research 33: 1227-1237. 1123-1127. Doi.org/10.1139/x03-048

30. Crawley, M. J. Johnston, A. E., Silvertown, J., Dodd, M., de Mazancourt, C., Heard, M. S., Henman, D. F., Edwards, G. R. 2005. Determinants of Species Richness in the Park Grass Experiment. The American Naturalist, 165: 180-192. Doi:doi.org/10.1086/427270

31. Foster, B.L., Dickson, T.L., Murphy,C.A., Karel, I.S. \&Smith, V.H. 2004. Propagule pools mediate community assembly and diversity-ecosystem regulation along a grassland productivity gradient. Journal of ecology 92 : 435-449. 10.1111/j.1461-0248.2007.01075.x

32. Connell, J. H., \&Orias, E. 1964. The ecological regulation of species diversity. American Naturalist 98:399-414.

33. Grime, J.P. 1973. Competitive exclusion in herbaceous vegetation. Nature (London) 242:344-347.

34. Preston, F. W. 1962. The canonical distribution of commonness and rarity. Ecology 43:185-215.

35. Goldberg, D. E., \& Miller, T. E. 1990. Effects of different resource additions on species diversity in an annual plant community. Ecology 71: 213-225.

36. Currie, D. J. 1991. Energy and large-scale patterns of animal- and plant-species richness. American Naturalist 137:27-39. DOoi: 10.1086/285144

37. Rosenzweig, M.L., Abramsky, Z. 1993. How are diversity and productivity related? In book: species diversity in ecological communities: historical and geographical perspectives. Editors: Ricklefs, R.E. and Schluter, D. University of Chicago Press. 1993.

38. Huston, M. A. \& DeAngelis, D. L. 1994. Competition and coexistence: the effects of resource transport and supply rates. The American Naturalist 144: 954-977. doi.org/10.1086/285720

39. Guo, Q., Berry, W.L. 1998. Species Richness and Biomass: Dissection of the hump-shaped relationships. Ecology 79(7): 2381-2396. Doi: 10.2307/176844

40. Gough,L., JGrace, J.B., Taylor, K.L. 1994. The relationship between species richness and community biomass: The importance of environmental variables. Oikos, 70: 271-279. Doi : 10.2307/3545638

41. Pastor, J., Downing, A.L., Erickson, H.E.1996. Species-Area curves and diversity-productivity relationships in beaver meadows of voyageurs national park, Minnesota, USA. Oikos 77(3):399-406

42. Naeem, S., Håkansson, K., Lawton, J.H., Crawley, M. J., Thompson, L.J. 1996. Biodiversity and Plant Productivity in a Model Assemblage of Plant Species. Oikos, 76: 259-264.

43. Vance-Chalcraft, H.D., Willig, M.R., Cox, S.B., Lugo, A.E., Scatena, F.N. 2010. Relationship between aboveground biomass and multiple measures of biodiversity in subtropical forest of Puerto Rico. Biotropica 42(3): 290-299. Doi: 10.1111/j.1744-7429.2009.00600.x

44. Liang, J., Watson, J.V., Zhou, M., Lei, X. 2016. Effects of productivity on biodiversity in forest ecosystems across the United States and China. Conservation Biology 30: 308-317. Doi: 10.1111/cobi.12636

45. Socher,S.A., Prati, D., Boch, S., Müller, J., Klaus, V.H., Hölzel, N. \& Fischer, M. 2012. Direct and productivity-mediated indirect effects of fertilization, mowing and grazing on grassland species richness. Journal of ecology 100: 1391-1399. DOI: 10.1111/j.1365-2745.2012.02020.x

46. Fraser, L.H., Pither, J. Jentsch, A., Sternberg, M., Zobel, M., Skarizadeh, D., et al. 2015. Worldwide evidence of a unimodal relationship between productivity and plant species richness. Science 349: 302-305. Doi. $10.1126 /$ science.aab3916

47. Duffy, J., Godwin, C. \& Cardinale, B. 2017. Biodiversity effects in the wild are common and as strong as key drivers of productivity. Nature, 549,261-264. Doi: org/10.1038/nature23886

48. Li, S., Su, J., Lang, X. et al. 2018. Positive relationship between species richness and aboveground biomass across forest strata in a primary Pinus kesiya forest. Scientific Report 8, 2227. Doi: 10.1038/s41598-01820165-y

49. Fichtner, A., Härdtle, W., Bruelheide, H. et al. 2018. Neighbourhood interactions drive overyielding in mixedspecies tree communities. Nature Communication 9, 1144 Doi: 10.1038/s41467-018-03529-w

50. Fichtner, A., Härdtle, W., Li, Y., et al. 2017. From competition to facilitation: how tree species respond to 
neighbourhood diversity. Ecology letters, 20(7): 892-900. Doi: 10.1111/ele.12786

51. Liang, M.X., Liu, X.,B., Parker, I.M., et al. 2019. Soil microbes drive phylogenetic diversity-productivity relationships in a subtropical forest. Science Advance, 5(10), eaax5088. DOI:10.1126/sciadv.aax5088

52. Allen,A.P., J.H.Brown \& Gillooly, J.F..2002. Global biodiversity, biochemical kinetics, and the energeticequivalence rule. Science 297: 1545-1548. 10.1126/science. 1072380

53. Stegen, J.C., Enquist, B.J., \& Ferriere, R.. 2009. Advancing the metabolic theory of biodiversity. Ecology Letters 12: 1001-1015. Doi: 10.1111/j.1461-0248.2009.01358.x

54. Wright, D.H. 1983. Species energy theory-an extension of species area theory. Oikos 41: 496-506.

55. Storch, D., Bohdalková, E., Okie, J. et al. 2018. The more - individuals hypothesis revisited: the role of community abundance in species richness regulation and the productivity-diversity relationship. Ecology letters, 21(6): 920-937. Doi: 10.1111/ele.12941

56. De Souza, F.C., Dexter,K.G., Phillips,O.L., et al. 2019. Evolutionary diversity is associated with wood productivity in Amazonian forests. Nature Ecology \& Evolution 3: 1754-1761. Doi: org/10.1038/s41559-0191007-y

57. Stevens, M.H.H. \& Carson, W.P. 1999. Plant density determines species richness along experimental gradients. Ecology, 80: 455-465. Doi: 10.2307/176625

58. Goldberg, D. E.\& Werner, P. 1983. Equivalence of competitors in plant communities: a null hypothesis and a field experimental approach. American Journal of Botany 70: 1098-1104.

59. Oksanen, J. 1996. Is the humped relationship between species richness and biomass an artefact due to plot size? Journal of ecology 84: 293-295. doi.10.2307/2261364

60. Adler, P.B., Seabloom, E.W., Borer, E.T., Hillebrand, H., Hautier, Y., Hector, A., et al. 2011. Productivity is a poor predictor of plant species richness. Science 333: 1750-1752. Doi: 10.1126/science.1204498.

61. Newman, E. I. 1973. Competition and diversity in herbaceous vegetation. Nature 244: 310.

62. Tilman, D. 1982. Resource competition and community structure. Princeton University Press, Princeton, New Jersey, USA.

63. Bongers, F., Poorter, F., Hawthorne, W.D., \& Sheil, D. 2009. The intermediate disturbance hypothesis applies to tropical forests, but disturbance contributes little to tree diversity. Ecology Letters 12: 798-805. Doi: 10.1111/j.1461-0248.2009.01329.x

64. Nuttle, T., Royo, A.A., Adams, M.B., \& Carson,W. P.. 2013. Historic disturbance regimes promote tree diversity only under low browsing regimes in eastern deciduous forest. Ecological Monographs 83: 3-17. Doi: $10.1890 / 11-2263.1$

65. Huston, M.A.2014. Disturbance, productivity, and species diversity: empiricism vs. logic in ecological theory. Ecology 95: 2382-2396. Doi:10.1890/13-1397.1

66. Pärtel, M., Zobel, M., Zobel, K., \& Maarel., E.V.D. 1996. The species pool and its relation to species richness: evidence from Estonian plant communities. Oikos 75:111-117. DOI: 10.2307/3546327

67. Zobel, M., Van der Maarel, E., \& Dupré, C. 1998. Species pool: the concept, its determination and significance for community restoration. Applied Vegetation Science 1: 55-66. Doi:10.2307/1479085

68. Rajaniemi, T. K., Goldberg, D. E., Turkington, R., \& Dyer, A. R. 2006. Quantitative partitioning of regional and local processes shaping regional diversity patterns. Ecology Letters 9: 121-128. Doi: 10.1111/j.14610248.2005.00855.x

69. Myers, J.A.,\& Harms, K.E.. 2009. Seed arrival, ecological filters, and plant species richness: a meta-analysis. Ecology Letters 12: 1250-1260. doi.org/10.1111/j.1461-0248.2009.01373.x

70. Lundholm, J.T., \&Larson, D.W. 2003. Relationships between spatial environmental heterogeneity and plant species diversity on a limestone pavement. Ecography 26: 715-722. DOI:10.1111/j.0906-7590.2003.03604.x

71. Dufour, A., Gadallah, F., Wagner, H.H., Guisan, A., \& Buttler, A. 2006. Plant species richness and environmental heterogeneity in a mountain landscape: effects of variability and spatial configuration. Ecography 29: 573-584. Doi. 10.1111/j.0906-7590.2006.04605.x

72. Yenni, G., Adler, P.B. \& Ernest, S.K.M. 2012.Strong self-limitation promotes the persistence of rare species. Ecology, 93, 456-461. Doi: 10.1890/11-1087.1

73. LaManna, J.A., Belote,R.T., Burkle,L.A.,et al. 2017.Negative density dependence mediates biodiversityproductivity relationships across scales. Nature Ecology \& Evolution 1: 1107-1115.

74. LaManna, J.A., Mangan, S.A., Alonso, A., et al. 2017. Plant diversity increases with the strength of negative density dependence at the global scale. Science 356 (6345), 1389-1392. Doi: 10.1126/science.aam5678 
75. Marquard, E., A.Weigelt, C.Roscher, M.Gubsch, A., Lipowsky,and B.Schmid. 2009. Positive biodiversityproductivity relationship due to increased plant density. Journal of Ecology 97: 696-704. Doi : 10.1111/j.1365-2745.2009.01521.x

76. Laughlin, D.C. 2014. Applying trait-based models to achieve functional targets for theory-driven ecological restoration. Ecology Letters 17: 771-784. doi.org/10.1111/ele.12288

77. Grossman, J.J., Cavender-Bares,J., Hobbie,S.E., et al. 2017. Species richness and traits predict overyielding in stem growth in an early - successional tree diversity experiment. Ecology, 98(10): 2601-2614. Doi : 10.1002/ecy.1958

78. Huston, M. A. 1979. A general hypothesis of species diversity. The American Naturalist 113:81-101.

79. Michalet, R., Brooker, R.W., Cavieres, L.A., Kikvidze, Z., Lortie, C.J., Pugnaire, F.I., Valiente-Banuet, A., \& Callaway, R.M. 2006. Do biotic interactions shape both sides of the humped-back model of species richness in plant communities? Ecology Letters 9: 767-773. Doi: 10.1111/j.1461-0248.2006.00935.x

80. Hughes, A.R., Byrnes, J.E., Kimbro, D.L., \& Stachowicz, J.J. 2007. Reciprocal relationships and potential feedbacks between biodiversity and disturbance. Ecology Letters 10: 849-864. Doi. 10.1111/j.1461-0248.2007.01075.x

81. Amarasekare, P. 2003. Competitive coexistence in spatially structured environments: a synthesis. Ecology letters 6: 1109-1122. Doi. 10.1046/j.1461-0248.2003.00530.x

82. Lasky, J.R., Uriarte, M., Boukili, V.K., Erickson, D.L., Kress, W.J., \& Chazdon, R.L. 2014. The relationship between tree biodiversity and biomass dynamics changes with tropical forest succession. Ecology Letters 17: 1158-1167. DOI: 10.1111/ele. 12322

83. Turnbull, L.A., Levine, J.M., Loreau, M., \& Hector, A. 2013. Coexistence, niches and biodiversity effects on ecosystem Functioning. Ecology Letters 16: 116-127. Doi: 10.1111/ele.12056

84. Huang, Y.Y., Chen,Y.X., Castro-Izaguirre,N. et al. 2018. Impacts of species richness on productivity in a large-scale subtropical forest experiment. Science, 362(6410):80-83. Doi: 10.1126/science.aat6405

85. Chiarucci, A., Viciani, D., Winter, C., \& Diekmann, M. 2006. Effects of productivity on speciesarea curves in herbaceous vegetation: evidence from experimental and observational data. Oikos 115: 475483.

86. Vilá, M., Vayreda, J., Comas, L., Ibáńez, J.J., Mata, T., \& Obón, B. 2007. Species richness and wood production: a positive association in Mediterranean forests. Ecology Letters 10: 241-250. Doi: 10.1111/j.14610248.2007.01016.x

87. Axmanová, I., Chytrý, M., Zelený, D., Li, C.F., Vymazalová, M., Danihelka, J., et al. 2012. The species richness-productivity relationship in the herb layer of European deciduous forests. Global Ecology and Biogeography 21:657-667.

88. Pierce, S. 2014. Implications for biodiversity conservation of the lack of consensus regarding the humped back model of species richness and biomass production. Functional Ecology, 28: 253-257.

Doi.org/10.1111/1365-2435.12147

89. Grace, J.B., Anderson, T.M., Smith, M.D., Seabloom, E., Andelman, S.J., Meche, G., et al. 2007. Does species diversity limit productivity in natural grassland communities? Ecology Letters 10: 680-689. Doi. 10.1111/j.1461-0248.2007.01058.x

90. Hastings, A. 1980. Disturbance, coexistence, history, and competition for space. Theoretical Population Biology 18:363-373.

91. Thompson K. 1987. The resource ratio hypothesis and the meaning of competition. Functional Ecology, 1: 297-315.

92. Kadmon,R., \& Benjamini, Y..2001. Effects of productivity and disturbance on species richness: a neutral model. The American Naturalist 167: 939-946. Doi: 10.1086/504602

93. Kondoh, M. 2001.Unifying the relationship of species richness to productivity and disturbance. Proceedings of the Royal Society B: Biological Science 268: 269-271. Doi. 10.1146/annurev.ecolsys.30.1.257

94. Mouquet N, Moore J, Loreau M. 2002. Plant species richness and community productivity: Why the mechanism that promotes coexistence matters. Ecology Letters 5(1) 56-65. Doi : 10.1046/j.14610248.2002.00281.x

95. Tilman, D., Lehman C.L., Thomson K.T. 1997. Plant diversity and ecosystem productivity: Theoretical considerations. Proceedings of National Academic of Science 94: 1857-1861.

96. Loreau, M. 1998. Biodiversity and ecosystem functioning: A mechanistic model. Proceedings of National Academic of Science USA 95: 5632-5636. doi.org/10.1073/pnas.95.10.5632 
97. Chen,Y., Huang,Y.Y., Niklaus,P.A., et al. 2020.Directed species loss reduces community productivity in a subtropical forest biodiversity experiment. Nature Ecology \& Evolution 4: 550-559. Doi.org/10.1038/s41559020-1127-4

98. Allcock, K.G., \& Hik, D.S.. 2003. What determines disturbance-productivity-diversity relationships? The effect of scale, species and environment on richness patterns in an Australian woodland. Oikos 102: $173-185$. 10.1034/j.1600-0706.2003.12345.x

99. Laforest-Lapointe, I., Paquette,A., Messier,C., et al. 2017. Leaf bacterial diversity mediates plant diversity and ecosystem function relationships. Nature 546: 145-147. Doi:10.1038/nature22399 